\title{
Effect of Synthesis Conditions on the Molecular Weight and Activation Energy of Urea-Formaldehyde Prepolymer and Their Relationship
}

\author{
Atqiya Anjum and G. M. Arifuzzaman Khan* \\ Department of Applied Chemistry and Chemical Engineering, Faculty of Engineering and Technology, Islamic University, \\ Kushtia-7003, Bangladesh
}

Received: November 09, 2020, Revised: December 10, 2020, Accepted: December 10, 2020, Available Online: December 13, 2020

\begin{abstract}
The aim of this study is to find out the viscosity change of urea-formaldehyde (UF) resin with the synthesis parameters namely formaldehyde/urea ( $\mathrm{F} / \mathrm{U})$ mole ratios, $\mathrm{pH}$ and temperature. The viscosity of UF resins, related to molecular weight and activation energy is very important factor of their usability. Urea-formaldehyde (UF) prepolymer was synthesized through polycondensation reaction with $\mathrm{F} / \mathrm{U}$ ratio $0.8,1.0,1.2,1.4,1.6$. The synthesis was carried out by two steps: alkali catalysis at reaction $\mathrm{pH} 8.3,90^{\circ} \mathrm{C}$ for 60 min and thereafter acid catalysis at $\mathrm{pH} 4.3,83^{\circ} \mathrm{C}$ for $15 \mathrm{~min}$. Viscosity of prepolymer was determined at acid catalysis step by simple glass viscometer. Weight average molecular weight $(M w)$ was calculated from the viscosity data of UF prepolymer using Mark-Houwink equation. Highest $M w$ (2020.9) of prepolymer was obtained at $\mathrm{F} / \mathrm{U}$ molar ratio 1.0 and $\mathrm{pH} 4.3$. In addition, it was found that $\mathrm{pH} 4.0$ yielded greater $M w$ (2049) UF prepolymer among the four reactions which were performed at $\mathrm{pH} 4.0,4.3,4.7$, and 5.0. The energy of activation $\left(E_{a}\right)$ of UF prepolymer was also calculated from the measured viscosity at temperature $70,75,80$ and $85^{\circ} \mathrm{C}$. The highest values of $E_{a}$ were also found at $\mathrm{F} / \mathrm{U}$ molar ratio 1.0 and $\mathrm{pH} 4.0$ \& lowest values was obtained at $\mathrm{F} / \mathrm{U}$ molar ratio 1.6 and pH 5.0. From the experimental data, it was shown that the values of $E_{a}$ and $M w$ were varied comparably with the change of reaction parameters.
\end{abstract}

Keywords: Urea-formaldehyde Prepolymer; F/U Molar Ratio; pH; Viscosity; Molecular Weight; Activation Energy.

This work is licensed under a Creative Commons Attribution-NonCommercial 4.0 International

\section{Introduction}

Thermosetting polymers are used widely in various field like thermal and electrical insulation, utensils, building materials, engineering tools etc. due its hardness and good resistance to electric and heat [1]-[2]. However, their use become limited due to their inherent properties for instance low toughness, low flexibility, non-recyclable, difficult to coloration etc. [3]. To overcome the drawbacks and value addition, plenty of research have been carried out by the polymer scientists [4]. Some of those researches explore alternative use of thermosetting polymers where drawbacks are not considered. The use of formaldehyde based resin as adhesives of particle board, plywood has ushered in a new era [5]-[9]. These resins not only have adhesive properties but also have long lasting capacity because they contain some fraction of free formaldehyde. For this particular case, those compounds are unusable for making medical goods and food grade materials [10]. Among the formaldehyde based thermosetting resin, phenol formaldehyde resin is widely used in adhesive, wood and composite industries [11]. Nevertheless, phenol formaldehyde belongs phenolic resin is comparatively harmful to the environment [12]. Moreover, it is better to use urea formaldehyde because it is cheap in price, possess good quality, less foul-smelling and has a beautiful color [5], [13]-[14].

Urea formaldehyde resin is prepared by the polycondensation reaction of urea and formaldehyde (Scheme 1) [8]. The synthesis process of urea-formaldehyde may be divided into two stages, addition or alkaline methylolation and acidic condensation. At alkaline methylolation, dimer, trimer with low molecular weight methylol urea is formed by substitution reaction of urea and formaldehyde. Thereafter, with the change of reaction condition of acidic condensation relatively higher molecular compound might be obtained. In this stage polymerization is propagated by the formation of methylene ($\left.\mathrm{CH}_{2}^{-}\right)$and dimethylene ether $\left(-\mathrm{CH}_{2}-\mathrm{O}-\mathrm{CH}_{2}-\right)$ linkages with the reaction of methylol group and amino group [14]. Sun et al. studied the effect of catalysts on the UF resin preparation [17]. They found that in alkali catalyzed reaction, limited amount of UF prepolymer was formed and a large amount of free urea left. On the other hand acid catalyst enhanced the formation of methylene, ether linkages, and urons. Gonçalves et al. reported that degree of condensation is higher on the alkaline-acidic combined process than only strong acid catalyze stage [18].

The reaction parameter namely urea/formaldehyde $(\mathrm{F} / \mathrm{U})$ molar ratio, temperature, $\mathrm{pH}$ etc. are the major factor controlling the condensation reaction [19]-[22]. Dazmiri et al. stated that amount of free formaldehyde in resin increases at higher $\mathrm{F} / \mathrm{U}$ ratio [21]. On the other hand, at low $\mathrm{F} / \mathrm{U}$ ratio some unreacted urea remains in resin. In addition, high molecular weight UF resin is formed at strong acidic condition and high temperature [5]. The UF resin is converted into solid after curing with suitable crosslinking agent and curing condition. However, setting time of polymer resin should be longer. For quick solidification, unreacted urea and formaldehyde is remained in polymer and high molecular weight is seldom formed. One of big problem of thermosetting polymer is that, it could not melt or reshape if once it solidified. Therefore, it should keep in liquid state before use. It is mandatory to retain it in liquid form when use for adhesive purposes, because resin should be spread evenly on the solid 
<smiles>NC(N)=O</smiles>

$\mathrm{NH}_{2}-\mathrm{NH}_{2}$

$\mathrm{H}^{\prime}$<smiles>O=C(NCO)NCO</smiles>

(II)<smiles>NC(=O)N(CO)CO</smiles><smiles>O=C(NCO)N(CO)CO</smiles>

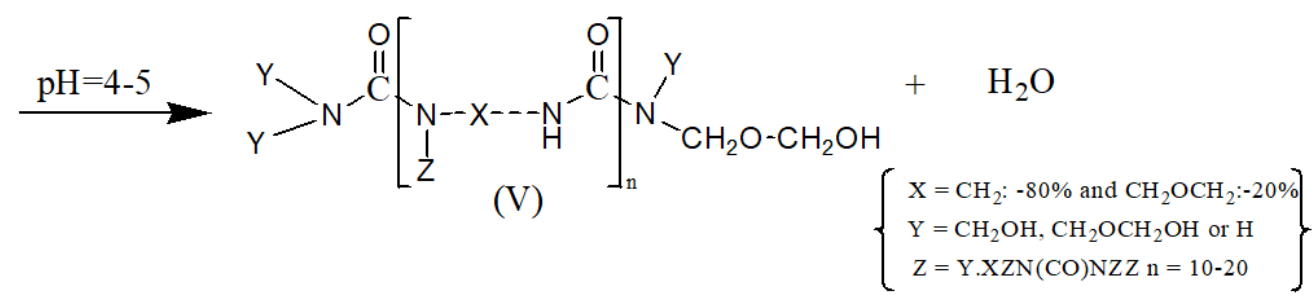

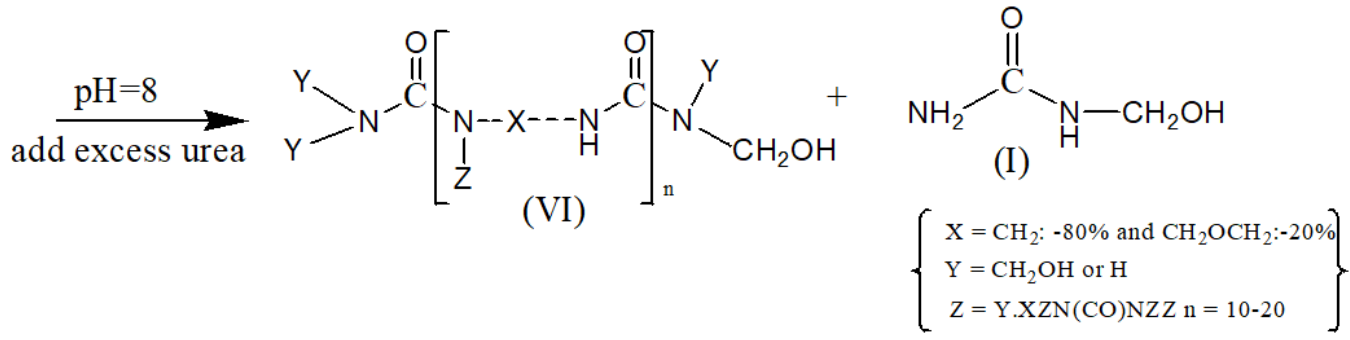

Scheme 1 Synthesis of UF resin from urea and formalin (I)-monomethylol urea,(II), (III)-dimethylol urea (IV)-trimethylol urea and $(\mathrm{V}),(\mathrm{VI})$-uron derivatives.

surface. For blending with other materials purposes, it is also important to apply the resin in a liquid state. The use ability of liquid resin is depended on its viscosity [13], [23]-[24]. The low viscous resin can penetrate and spread easily on broad panel when use in adhesive purposes. The viscosity of a polymer adhesive is controlled by temperature, $\mathrm{pH}$ and concentration. Plenty of researches have been studied the effect of reaction parameters on the viscosity of UF resin [24]-[25]. They interpreted the experimental results differently. Since crosslinking reaction of uron derivatives takes place with condensation reaction, it is very difficult to get reproduce values. Different results can also be obtained due to the differences in the environment. That why, we have chosen the current topic to know the changes of viscous properties in our reaction setting.

The molecular weight of UF resin were measured by using gel permeable chromatography (GPC), NMR, viscometry etc. [13], [26]. Viscometry is very simple technique which able to provide important information of viscous polymer solution [27]. The viscosity of fluids is determined both by collision among particles and by the force fields which determines interactions among molecules. It has great analytical significant for the characterization of polymer molecules. As like viscosity, activation energy $\left(E_{a}\right)$ is important property of viscous polymer solution which influence on solvent types, concentration of solution, etc. [28]. DSC is most common technique to measure the activation energy $\left(E_{a}\right)$ of UF resin [29]. $E_{a}$ can be calculated if viscosities of solution change with temperature. The viscosity of polymer solution is varied with temperature which has been investigated in previous studies [30]-[31]. The $E_{a}$ could be calculated from viscosity-temperature data using Kissinger equation [32]. No published data has been found which determine the value of $E_{a}$ of UF resin by viscosity measurement. In addition, no clear information is available in the literature which depicted the relation of $E_{a}$ with synthesis parameter of UF resin $(\mathrm{F} / \mathrm{U}$ molar ratio and $\mathrm{pH})$. In the present research, attempt has been taken to find the value of $M w$ and $E_{a}$ of UF prepolymers by viscosity measurement. A set of experiment has carried out to correlate the values of $M w$ and $E_{a}$.

\section{Experimental}

\subsection{Materials}

The technical grade urea granules $(99 \%)$ and formalin (37\%) were purchased from Merck, India. The other reagents used in this study were analytical grade.

\subsection{Methods}

\subsubsection{Synthesis of UF prepolymer}

UF prepolymer was prepared by conventional method with various $\mathrm{F} / \mathrm{U}$ mole ratios of $0.8,1.0,1.2,1.4$, and 1.6 [20]. This method is divided into two parts: (1) alkali catalysis: $405 \mathrm{ml}$ formalin was taken in open glass reactor $(1000 \mathrm{ml}$ Pyrex beaker) equipped with a thermometer and heater with stirrer. The urea was added in two steps and in each step 50\% of it was used. The $50 \%$ of solid urea (predetermined) was dissolved in formalin under stirring at $40^{\circ} \mathrm{C}$. The $\mathrm{pH}$ was adjusted to $7.8-$ 8.0 by adding $0.01 \mathrm{M}$ sodium hydroxide solution. The reactor 
was heated to $90^{\circ} \mathrm{C}$ and maintained for $60 \mathrm{~min}$. The temperature was then cooled to $80^{\circ} \mathrm{C}$. (2) Acid catalysis: at $83^{\circ} \mathrm{C}$, the $\mathrm{pH}$ was adjusted to 4.3 by adding $0.05 \mathrm{M}$ acetic acid solution. The rest amount of urea was then added in solution and stirred continuously for $15 \mathrm{~min}$ at $83^{\circ} \mathrm{C}$ to complete dissolution of urea. White viscous suspension of UF resin prepolymer was obtained. The prepolymer was then kept at room temperature for slowing down the curing reaction. All the viscosities of the solution were quickly measured at same time by Ostwald viscometer. For comparative analysis, a set of prepolymer was prepared using $\mathrm{F} / \mathrm{U}$ mole ratio 1.0 by maintaining $\mathrm{pH} 4.0,4.3$, 4.7 and 5.0 at acid catalysis step.

\subsubsection{Molecular weight determination}

For molecular weight determination, the solutions of resin sample $(0.01,0.02,0.03,0.04$ and $0.05 \mathrm{ml} / 1 \mathrm{ml})$ were prepared using mixed solvent Ethanol/water (1:1) just before performing the experiment [24]. Then the viscometric flow times were measured for the samples. By using measured flow time of a solution, viscosity is calculated by Poiseuille's law at following equation [13]:

$\eta=\frac{\pi r^{4} p t}{8 l v}$

Where, $\eta$, kinematic viscosity, $v$, volume of solution, $r \& l$ are radius and length of the capillary tube of viscometer respectively, $t$, falling time through the capillary tube at pressure $(p)$. The falling time is measured for the level of the liquid to pass between the two marks is proportional to the pressure imposed by gravity on the head of the liquid by a known volume.

By simplifying equation 1 the relative viscosity $\left(\eta_{r}\right)$ and specific viscosity $\left(\eta_{s p}\right)$ can be determined as:

$\eta_{r}=\frac{\eta}{\eta_{o}}=\frac{t}{t_{o}}$

$\eta_{s p}=\frac{\eta-\eta_{o}}{\eta_{o}}=\frac{t-t_{o}}{t_{o}}$

$\eta_{o}$ is viscosity of the solvent, $t$ is flow time of solution and $t_{o}$ is flow time of solvent. The intrinsic viscosity $[\eta]$ is a measure of molecular dimension and is defined as

$[\eta]={ }_{c} \underset{\rightarrow t}{\operatorname{Lt}} \frac{\eta_{s p}}{C}={ }_{c}{\underset{\operatorname{Lt}}{\rightarrow}}_{0} \frac{\ln \eta_{r}}{C}$

$\eta_{s p} /_{C}$, reduced viscosity of the solution; $\ln \eta_{r} /_{C}$, inherent viscosity; and $\mathrm{C}$, the concentration of solution in $\frac{g}{100 \mathrm{ml}}$. The following empirical equation might be work efficiently for dilute solution.

$\eta_{s p} /_{C}=[\eta]+K_{1}[\eta]^{2} C--($ Huggins $)$

$\ln \eta_{r} /_{C}=[\eta]+K_{2}[\eta]^{2} C--($ Kraemer $)$

If a graph is made by plotting the observed reduced or inherent viscosities against the concentration, the intercept of the straight line at $\mathrm{C}=0$ gives the intrinsic viscosity.
From the measured intrinsic viscosity, the molecular weight was calculated using modified staudinger equation [31]:

$[\eta]=K M^{\alpha}$

From the intercept of the plot $\log [\eta]$ against $\log M$, values of $\mathrm{K}$ and from the slope, value of ' $\alpha$ ' were found. The values of ' $\mathrm{K}$ ' and ' $\alpha$ ' were found to be $0.74 \times 10^{-3}$ and 1.05 respectively [33].

\subsubsection{Activation energy measurement}

Viscosity was measured by Ostwald viscometer at 70, 75, 80,85 and $90^{\circ} \mathrm{C}$ in a thermostatic water bath (for activation energy determination). The viscometer was fixed vertically into water bath where the highest level of the liquid in the viscometer was at least one centimeter below the water level in the bath. The prepared of prepolymer samples were quickly taken into the viscometer upto the mark. Since the viscosity of resin continuously changed with time, the viscometer containing experimental solution was allowed to stand only for about five minutes to attain the temperature of i.e. constant temperature bath before each measurement. Minimum 10 falling time was observed by stop watch for each experiment. After every measurement the viscometer was washed thoroughly and then checked by measuring the time of flow of distilled water. This energy is called the 'activation energy of viscous flow' $\left(E_{a}\right)$. $E_{\mathrm{a}}$ is calculated using Eyring's equation [34] (equation 8 \& 9).

$\eta=A e^{\frac{E_{a}}{R T}}$

$\ln \eta=\frac{E_{a}}{R T}+\ln A$

The value of $E_{a}$ is calculated from the slope of plot of $\ln \eta$ versus $1 / \mathrm{T}$ by using equation 9 . The value of $\mathrm{R}$ is considered $8.314 \mathrm{~J} \mathrm{~K}^{-1} \mathrm{~mol}^{-1}$.

\section{Results and Discussion}

The viscosities of UF prepolymer prepared at different $\mathrm{F} / \mathrm{U}$ molar ratio $0.8,1.0,1.2,1.4,1.6$ and $\mathrm{pH} 4.0,4.3,4.7,5.0$ are calculated from measured falling time at temperature $83^{\circ} \mathrm{C}$. The falling time of solvent ethanol:water (1:1) was taken as reference sample. Every UF prepolymer sample taken for viscosity measurement is preserved at same condition.

The concentration of resin solution versus calculated reduce viscosity is plotted in Fig. 1. All the line presented in the figure of UF prepolymer with different $F / U$ molar ratio shown the similar trend. The intrinsic viscosity is calculated from the intersection of those lines to $\mathrm{Y}$ axis. Microsoft excel software is used to get exact values. Weight average molecular weight $(M w)$ is obtained from intrinsic viscosity by MarkHouwink equation and the values are given in Table 1. It has been noted that the intrinsic viscosity and $M w$ of the resins prepared at different $\mathrm{F} / \mathrm{U}$ molar ratio under the same acid $\mathrm{pH}$ with the same condensation time and temperature are different. The highest $M w$ (2020.9) is found at $\mathrm{F} / \mathrm{U}$ molar ratio 1.0 then decreases with the increase of F/U molar ratio. The lowest $M w$ is found 1735.7 at greater $\mathrm{F} / \mathrm{U}$ molar ratio 1.6. At higher urea proportions (lower $\mathrm{F} / \mathrm{U}$ ), the condensation reaction is faster. This may be due at low F/U molar ratio more amine groups 
available to react with formaldehyde [21]. It is also assumed that the gel time which directly related to viscosity is significantly affected by molar ratios. Moreover, at very low $\mathrm{F} / \mathrm{U}$ molar ratio $(0.8)$ urea is not disintegrated completely in formalin. M. Dunkey also reported some portion of resin was precipitated at lower $\mathrm{F} / \mathrm{U}$ ratio $(>0.9)$ during the acid condensation step, causing inhomogenities in the solutions [5]. No remarkable differences are shown in resin density. The $\mathrm{R}^{2}$ values indicate better correlation between reduced viscosity and concentration of resin solution.

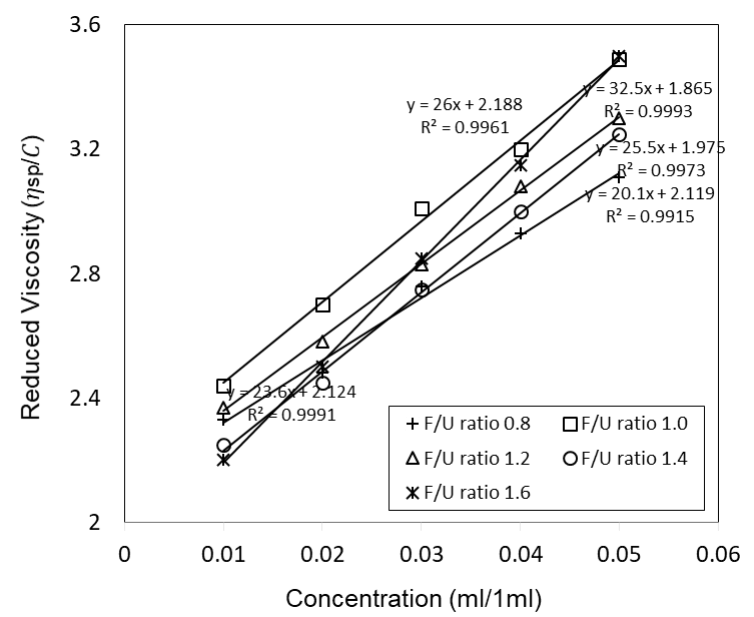

Fig. 1 Reduced viscosity vs concentration plot of UF prepolymers of different $\mathrm{F} / \mathrm{U}$ molar ratio.

The intrinsic viscosities of UF prepolymer at $\mathrm{pH} 4.0, \mathrm{pH}$ 4.3, $\mathrm{pH} 4.7$ and $\mathrm{pH} 5.0$ for $\mathrm{F} / \mathrm{U}$ molar ratio 1.0 are obtained from Fig. 2 and the respective values of $M w$ are 2049, 2020, 1833, and 1726 respectively which shown in Table 1 . The polymerization process of UF resin is propagated in the acid condensation step. The linear or branched molecules with medium and even higher $M w$ are formed with the reaction of methylols, urea and free formaldehyde. The numbers of stable methylene $\left(-\mathrm{CH}_{2}-\right)$ linkages are increased at lower $\mathrm{pH}$ and high temperature [5]. The highest $M w$ is found at $\mathrm{pH} 4.0$ and became lowest at $\mathrm{pH}$ 5.0. The results indicate that molecular weight of UF resin is increasing with the decrease of reaction $\mathrm{pH}$. The high percentage of uron derivatives might be formed under strong acidic conditions formulated in the past [34].

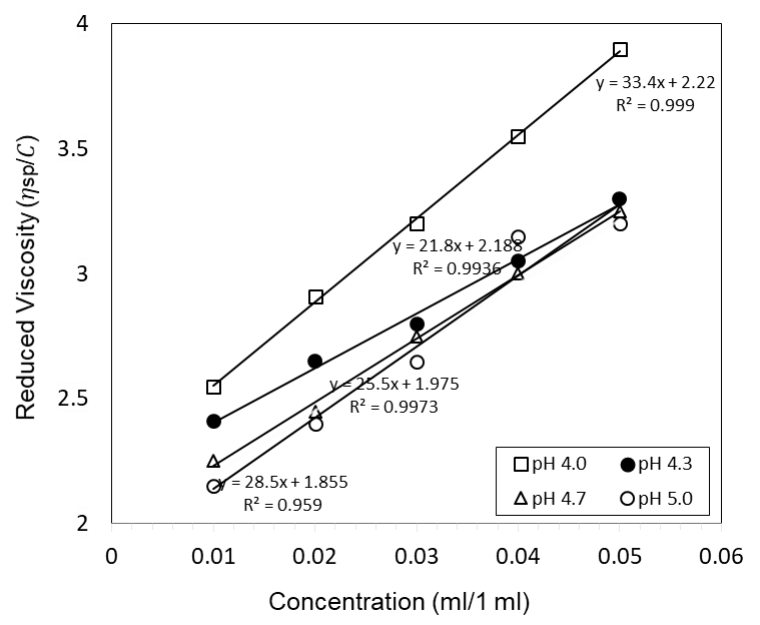

Fig. 2 Reduced viscosity vs concentration plot of UF prepolymers of different $\mathrm{pH}$.

The change of viscosity with temperature variation can be explained the molecular movement in the solvent. It has been seen that molecular movement increases with the increase of temperature and hence decrease the viscosity. At high temperature the kinetic energy of the molecule increases and starts to move more rapidly and away from each other. Due to rapid movement of molecule at higher temperature, more bulk space is formed which diminishes interlayer movement restriction and therefore viscosity decreases. The increase of viscosity with the decrease of temperature is shown in Fig. 3. The plot shown, the viscosity of the prepolymer of different F/U molar ratio with temperatures gives similar trend. The resin contains higher formalin fraction exhibit lower viscosity values. In other word, concentrate solution have higher viscosities than dilute solution. Molecules of concentrate solution should have energy which overcomes the internal friction or resistance of fluid.

Table 1 Values of intrinsic viscosity, $M w$ and $E a$ at various reaction condition.

\begin{tabular}{|c|c|c|c|c|c|c|c|c|}
\hline \multirow[b]{2}{*}{$\mathrm{F} / \mathrm{U}$ ratio } & \multirow[b]{2}{*}{$\mathrm{pH}$} & \multirow{2}{*}{$\begin{array}{l}\text { Density } \\
\left(\mathrm{gm}_{\mathrm{cm}} \mathrm{cm}^{-3}\right)\end{array}$} & \multicolumn{3}{|c|}{ Molecular weight $(M w)$} & \multicolumn{3}{|c|}{ Energy of activation $\left(E_{\mathrm{a}}\right)$} \\
\hline & & & {$[\mathrm{n}]$} & $\mathrm{R}^{2}$ & $M w$ & $\delta y / \delta x$ & $\mathrm{R}^{2}$ & $E_{\mathrm{a}}\left(\mathrm{kj} \cdot \mathrm{mol}^{-1}\right)$ \\
\hline 0.8 & 4.3 & 1.56 & 2.119 & 0.9915 & 1960.1 & 124.17 & 0.9873 & 1.0323 \\
\hline 1 & 4.3 & 1.52 & 2.188 & 0.9961 & 2020.9 & 131.88 & 0.9963 & 1.0965 \\
\hline 1.2 & 4.3 & 1.49 & 2.124 & 0.9991 & 1964.5 & 124.45 & 0.9993 & 1.0347 \\
\hline 1.4 & 4.3 & 1.47 & 1.975 & 0.9993 & 1833.1 & 120.88 & 0.9894 & 1.0050 \\
\hline 1.6 & 4.3 & 1.44 & 1.865 & 0.9973 & 1735.7 & 118.17 & 0.9877 & 0.9825 \\
\hline 1 & 4.0 & 1.51 & 2.220 & 0.9990 & 2049.0 & 144.87 & 0.9986 & 1.2044 \\
\hline 1 & 4.3 & 1.52 & 2.188 & 0.9936 & 2020.9 & 131.8 & 0.9963 & 1.0958 \\
\hline 1 & 4.7 & 1.51 & 1.975 & 0.9973 & 1833.1 & 117.55 & 0.9652 & 0.9773 \\
\hline 1 & 5.0 & 1.49 & 1.855 & 0.9590 & 1726.8 & 114.88 & 0.9796 & 0.9551 \\
\hline
\end{tabular}




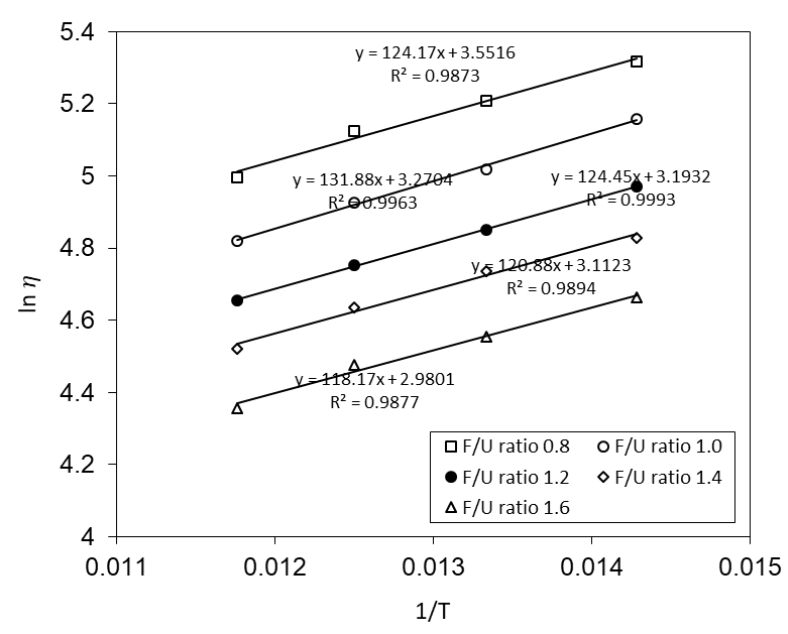

Fig. 3 Variation of viscosity of UF prepolymer with different $\mathrm{F} / \mathrm{U}$ ratio at temperature $70,75,80$ and $85^{\circ} \mathrm{C}$.

According to Fig. 3, the steepness of all line graphs belongs to prepolymer resin of different $\mathrm{F} / \mathrm{U}$ molar ratio looks similar. The resin prepared at $\mathrm{F} / \mathrm{U}$ molar ratio 1.0 exhibit slightly steeper slope in the Eyring plot than other UF prepolymer. The calculated $E_{a}$ for the different concentrations are given in Table 1 . The $E_{a}$ value of UF prepolymer prepared at $\mathrm{F} / \mathrm{U}$ molar ratio $0.8,1.0,1.2,1.4$ and 1.6 is calculated and the values are $1.0323,1.0965,1.0347,1.0050$ and $0.9825 \mathrm{~kJ} \mathrm{~mol}^{-1}$ respectively. It has been seen that the energy of activation is increased upto F/U molar ratio 1.0 and then decreased with the increase of formaldehyde content. The molecular mobility is decreased due to reduction of frictional resistance and hence decreases $E_{\text {a }}$. However, $E_{\text {a }}$ of $\mathrm{UF}$ resin at F/U molar ratio 0.8 lower than resin found at $\mathrm{F} / \mathrm{U}$ molar ratio 1.0 . Probably at high proportion of urea is made precipitation at unreacted form during polycondensation reaction [5]. The previous studies also stated that the solid content of UF resin is greater at higher $\mathrm{F} / \mathrm{U}$ molar proportion [25].

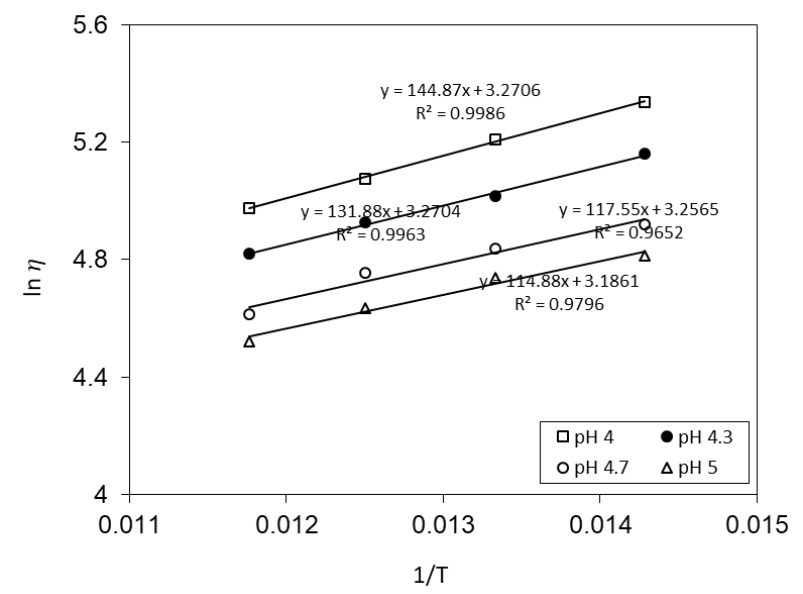

Fig. 4 Variation of viscosity of UF prepolymer with various $\mathrm{pH}$ at temperature $70,75,80$ and $85^{\circ} \mathrm{C}$.

Fig. 4 illustrated the change of viscosity of UF prepolymer prepared by different $\mathrm{pH}$ with temperature. It has been seen that the viscosity decreases with the increase of $\mathrm{pH}$. In the experiment the higher molecular weight is found at $\mathrm{pH}$ 4.0. According to the studies of Tomita [35] known that lower $\mathrm{pH}$ favors the synthesis process of UF resin i.e. high molecular weight compound is formed at very strong acidic condition. Lee and Kim also declared that the mobility of the UF resin molecules and their reactive groups decreases when the molecular weight increases. In addition, molecules are crosslinked on the curing process which reduce the mobility significantly [36]. Therefore, the activation energy is found greater at lowest $\mathrm{pH}$. The calculated values of $E a$ are $120.44 \times 10^{-2}, 109.58 \times 10^{-2}, 97.73 \times 10^{-2}$ and $95.51 \times 10^{-2}$ is found at $\mathrm{pH} 4.0,4.3,4.7$ and 5.0 respectively. The $\mathrm{R}^{2}$ values indicate better correlation between temperature and $\ln \eta$.

Fig. 5 presented the relation of between molecular weight and activation energy of UF resin prepared by various $F / U$ molar ratio and reaction $\mathrm{pH}$. The similar trend of $E_{a}$ and $M w$ curves is shown. The highest values of $E_{a}$ and $M w$ are found at $\mathrm{F} / \mathrm{U}$ molar ratio 1.0 and lowest values found at 1.6. Similarly, highest $E_{a}$ and $M w$ are obtained at $\mathrm{pH} 4$ and thereafter their values are decreased with the increase of $\mathrm{pH}$.

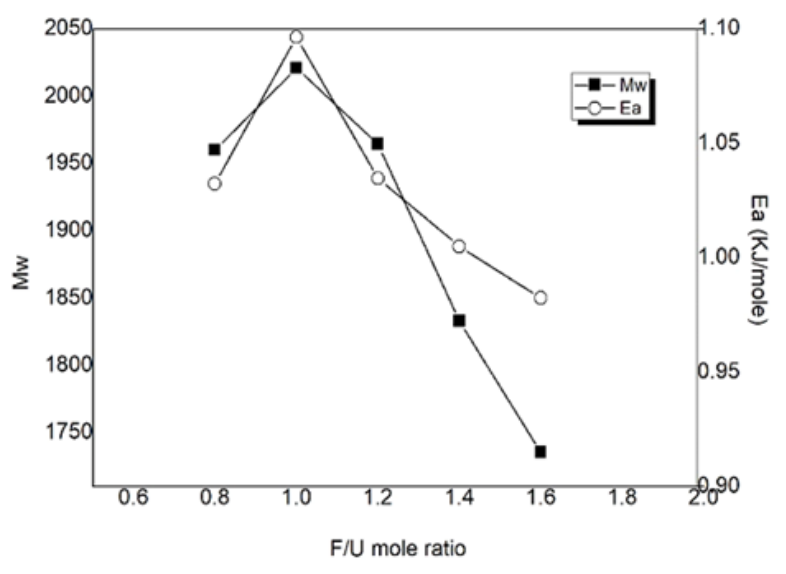

(a)

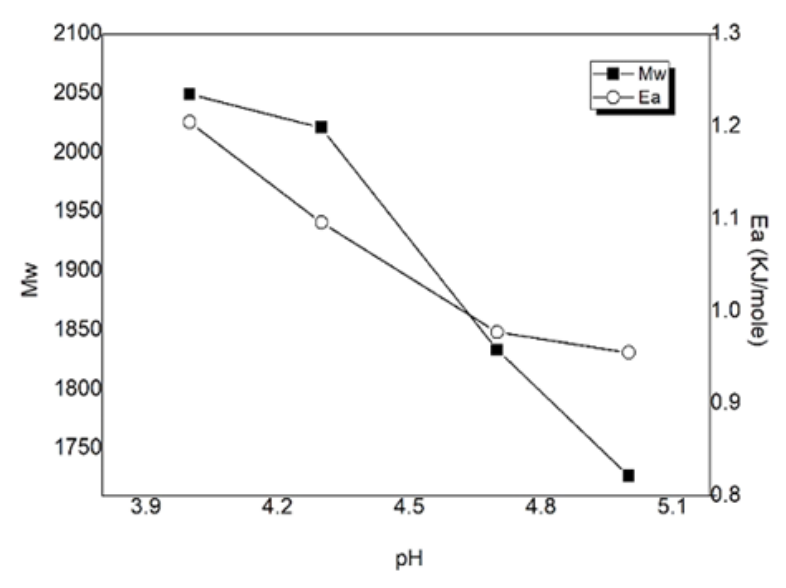

(b)

Fig. 5 Change of Mw and Ea of UF prepolymer prepared by various $\mathrm{F} / \mathrm{U}$ ratio and $\mathrm{pH}$

\section{Conclusion}

This paper describes the change of molecular weight $(M w)$ and activation energy (Ea) of urea-formaldehyde (UF) prepolymer prepared by $\mathrm{F} / \mathrm{U}$ molar ratio $0.8,1.0,1.2,1.4,1.6$ at $\mathrm{pH}$ 4.3. Another set of UF prepolymer made at $\mathrm{pH} 4.0,4.7$, 5.0 with F/U molar ratio 1.0. The value of $M w$ calculated from 
intrinsic viscosity using Mark-Houwink (M-H) equation. The results showed that $M w$ of UF prepolymer varied remarkably with reaction parameters. The highest $M w$ was found at $\mathrm{F} / \mathrm{U}$ molar ratio 1.0 and $\mathrm{pH}$ 4. The activation energy $\left(E_{a}\right)$ of UF prepolymer samples calculated by Eyring's equation from intrinsic viscosity measured at temperature 70, 75, 80 and $85^{\circ} \mathrm{C}$. The value of $E_{a}$ changed with the variation of reaction parameter like $M w$. Activation energy decreased at higher F/U mole ratio and $\mathrm{pH}$ value. The consistent of viscosity data of UF prepolymer samples given similar trend in $M w$ and $E_{a}$ values change of with reaction parameter. Finally, it may suggest that the viscosity measurement is quite effective method for determination activation energy of UF resin.

\section{References}

[1] Moser, A. and Feuchter, M., 2016. Mechanical properties of composites used in high-voltage applications. Polymers, 8(7), p.260.

[2] Post, W., Susa, A., Blaauw, R., Molenveld, K. and Knoop, R.J., 2020. A review on the potential and limitations of recyclable thermosets for structural applications. Polymer Reviews, 60(2), pp.359-388.

[3] Jeong, D.H., Park, J.W., Jeon, Y.J. and Lee, J.H., 2019, October. Development of Thermoplastic Materials for the Application of Eco-friendly. In 2019 5th International Conference on Electric Power Equipment-Switching Technology (ICEPE-ST) (pp. 476-479). IEEE.

[4] Tao, L., Sun, Z., Min, W., Ou, H., Qi, L. and Yu, M., 2020. Improving the toughness of thermosetting epoxy resins via blending triblock copolymers. RSC Advances, 10(3), pp.1603-1612.

[5] Dunky, M., 1998. Urea-formaldehyde (UF) adhesive resins for wood. International Journal of Adhesion and Adhesives, 18(2), pp.95-107.

[6] Khan, G.M.A., Abedin, S.M.A., Choudhury, M.J., Gafur, M.A. and Alam, M.S., 2014. Renewable okra bast fiber reinforced phenol formaldehyde resin composites: mechanical and thermal studies. Res Rev: J Mater Sci, 2, pp.32-36.

[7] Khan, G.A., Haque, M.A. and Alam, M.S., 2014. Studies on okra bast fibre-reinforced phenol formaldehyde resin composites. In Biomass and Bioenergy (pp. 157-174). Springer, Cham.

[8] No, B.Y. and Kim, M.G., 2004. Syntheses and properties of low-level melamine-modified urea-melamineformaldehyde resins. Journal of Applied Polymer Science, 93(6), pp.2559-2569.

[9] Sreekala, M.S., Kumaran, M.G., Joseph, S., Jacob, M. and Thomas, S., 2000. Oil palm fibre reinforced phenol formaldehyde composites: influence of fibre surface modifications on the mechanical performance. Applied Composite Materials, 7(5-6), pp.295-329.

[10] Kariuki, S.W., Wachira, J., Kawira, M. and Murithi, G., 2019. Formaldehyde Use and Alternative Biobased Binders for Particleboard Formulation: A Review. Journal of Chemistry, 2019.

[11]Fink, J. K., 2013. Chapter 4 - Phenol/Formaldehyde Resins. In J. K. B. T.-R. P. F. and A. (Second E. Fink (Ed.), Plastics Design Library, pp. 155-177, William Andrew Publishing.

[12] Sarika, P.R., Nancarrow, P., Khansaheb, A. and Ibrahim, T., 2020. Bio-Based Alternatives to Phenol and
Formaldehyde for the Production of Resins. Polymers, 12(10), p.2237.

[13] Jeong, B. and Park, B.D., 2019. Practical relationship between apparent viscosity and molecular weight of ureaformaldehyde resin adhesives. Journal of Adhesion Science and Technology, 33(3), pp.209-216.

[14] Jeremejeff, J., 2012. Investigation of UF-resins-the Effect of the Formaldehyde/Urea Molar Ratio during Synthesis. Master of Science Thesis, pp.1-108.

[15]Que, Z., Furuno, T., Katoh, S. and Nishino, Y., 2007. Effects of urea-formaldehyde resin mole ratio on the properties of particleboard. Building and Environment, 42(3), pp.1257-1263.

[16]Dunky, M., 2017. Adhesives in the wood industry. Handbook of Adhesive Technology, Third Edition, pp.511-574.

[17] Sun, Q.N., Hse, C.Y. and Shupe, T.F., 2014. Effect of different catalysts on urea-formaldehyde resin synthesis. Journal of Applied Polymer Science, 131(16).

[18] Gonçalves, C., Pereira, J., Almeida, M., Paiva, N.T., Ferra, J.M., Martins, J.M., Magalhães, F.D., Barros-Timmons, A. and Carvalho, L.H., 2019. Impact of alkaline-acid and strongly acid process on the synthesis of ureaformaldehyde resins and derived composites: A comparison study. European Journal of Wood and Wood Products, 77(6), pp.1177-1187.

[19] Akinterinwa, A., Ismaila, A., \& Aliyu, B., 2020. Concise Chemistry of Urea Formaldehyde Resins and Formaldehyde Emission. Insights in Chemistry and Biochemistry, pp.1-6.

[20]Ferra, J.M., Mena, P.C., Martins, J., Mendes, A.M., Costa, M.R.N., Magalhães, F.D. and Carvalho, L.H., 2010. Optimization of the synthesis of urea-formaldehyde resins using response surface methodology. Journal of Adhesion Science and Technology, 24(8-10), pp.1454-1471.

[21] Dazmiri, M.K., Kiamahalleh, M.V., Dorieh, A. and Pizzi, A., 2019. Effect of the initial F/U molar ratio in ureaformaldehyde resins synthesis and its influence on the performance of medium density fiberboard bonded with them. International Journal of Adhesion and Adhesives, 95, p.102440.

[22] Nuryawan, A., Risnasari, I., Sucipto, T., Iswanto, A.H. and Dewi, R.R., 2017, July. Urea-formaldehyde resins: production, application, and testing. In IOP Conference Series: Materials Science and Engineering (Vol. 223, No. 1, p. 012053). IOP Publishing.

[23] Hepworth, D.G., Bruce, D.M., Vincent, J.F.V. and Jeronimidis, G., 2000. The manufacture and mechanical testing of thermosetting natural fibre composites. Journal of materials science, 35(2), pp.293-298.

[24] Osemeahon, S.A., Barminas, J.T. and Aliyu, B.A., 2007. Effect of urea formaldehyde viscosity on some physical properties of a composite from reactive blending of urea formaldehyde with natural rubber. International J Physical Sciences, 2(9), pp.242-248.

[25] Jeong, B. and Park, B.D., 2019. Effect of molecular weight of urea-formaldehyde resins on their cure kinetics, interphase, penetration into wood, and adhesion in bonding wood. Wood Science and Technology, 53(3), pp.665-685. 
[26]Liu, Y.Q., Tian, Y., Zhao, G.Z., Sun, Y.Y., Zhu, F.T. and Cao, Y., 2008. Synthesis of urea-formaldehyde resin by melt condensation polymerization. Journal of Polymer Research, 15(6), p.501.

[27] Rohindra, D.R., Lata, R.A. and Coll, R.K., 2012. A simple experiment to determine the activation energy of the viscous flow of polymer solutions using a glass capillary viscometer. European journal of physics, 33(5), p.1457.

[28] Chandler, H.D., 2013. Activation energy and entropy for viscosity of wormlike micelle solutions. Journal of colloid and interface science, 409, pp.98-103.

[29]Chen, Y.Z. and Xiao, H., 2017. Characterization of precuring behavior of urea-formaldehyde resin affected by different temperatures. $E \& E S, 77(1)$, p.012007.

[30] Budtova, T. and Navard, P., 2015. Viscosity-temperature dependence and activation energy of cellulose solutions. Nordic Pulp and Paper Research Journal, 30(1), pp.99104.

[31] Rohindra, D.R., Lata, R.A. and Coll, R.K., 2012. A simple experiment to determine the activation energy of the viscous flow of polymer solutions using a glass capillary viscometer. European journal of physics, 33(5), p.14571464.

[32] Nuryawan, A., Park, B.D. and Singh, A.P., 2014. Comparison of thermal curing behavior of liquid and solid urea-formaldehyde resins with different formaldehyde/urea mole ratios. Journal of Thermal Analysis and Calorimetry, 118(1), pp.397-404.

[33]Edoga, M.O., 1997. Stability Improvement of UreaFormaldehyde Adhesives for Wood Products (Doctoral dissertation, Ph. D Thesis submitted to Ahmadu Bello University, Zaria, Nigeria).

[34] Gedde, U.L.F., 1995. Polymer physics. Springer Science \& Business Media.

[35]Hse, C.Y., Xia, Z.Y. and Tomita, B., 1994. Effects of reaction $\mathrm{pH}$ on properties and performance of ureaformaldehyde resins. Holzforschung 48 (6): 527-532.

[36]Lee, Y.K. and Kim, H.J., 2013. Relationship between curing activation energy and free formaldehyde content in urea-formaldehyde resins. Journal of adhesion science and technology, 27(5-6), pp.598-609. 